\title{
Research on the Factors Influencing Labor Dispute and its Mechanism of Action in an Open Condition
}

\author{
Qiang Chen \\ School of Economics \\ Shanghai University \\ Shanghai, China, 200444
}

\author{
Xiaodong Jia \\ School of Economics \\ Shanghai University \\ Shanghai, China, 200444
}

\begin{abstract}
This paper discusses the influence of trade on labor dispute and its mechanism of action by introducing the inter-provincial panel data. The research result demonstrates that foreign trade can provoke the labor dispute to an extent where such labor dispute remains explicit. Further research shows the union plays a considerable role in the interaction between labor and capital.
\end{abstract}

Keywords-foreign trade; labor dispute; union; instrumental variable GMM

\section{INTRODUCTION}

Economic globalization has been greatly developed in China with the continuous expansion of international trade and unceasing inflow of FDI since the implementation of reform and opening up. As described in China Statistical Yearbook, China's dependence on foreign trade jumped to $62.5 \%$ in 2007 from $9.8 \%$ in 1978, and the total import and export value surged to USD 2176.57 billion from USD 20.64 billion (Tang Dongbo, 2012). By the end of 2012, the total import and export value summed up to USD 3867.12 billion, accounting for $47.1 \%$ of GDP, despite of a slowdown in recent years.

On the one hand, the rapid development of foreign trade, especially of processing trade, provides employment opportunities for hundreds of millions of agricultural population and stimulates large-scaled labor migration, which creates in turn China's urbanization on an unprecedented scale (Zhao Mingliang, 2011). On the other hand, compared to outstanding performance of economic growth and globalization, China's Labor Standards has been developed very slowly over the past ten years, leading to increasingly severe labor dispute (Cai Fang, 2012). In recent years, with the development of our economic society, especially on building a "Well-off" society in an all-round way, the conflict between labor and capital has been steeply intensified with an rising number of various extreme events related to labor-capital dispute, being one of critical factors influencing social stability (Wang Mingliang, 2013).

The data, as shown in China Labor Statistical Yearbook, indicates that the number of China's labor dispute cases accepted and heard in 2012 surged to 641,202 from 93,649 in 1996 due to China's accession to the WTO in 2001 and the promulgation of new "Labor Contract Law" in 2008. As shown in the Figure below, with further in-depth development of China's trade, there is a year-on-year increase in the number of labor dispute, which directly reflects the increasingly intensifying conflict between labor and capital.

Fig. 1. Number of China's Labor Dispute Cases, Total Import and Export Value and Processing Trade Value for 1998 - 2012

Import and Export Value, Processing Trade and Labor Dispute Cases

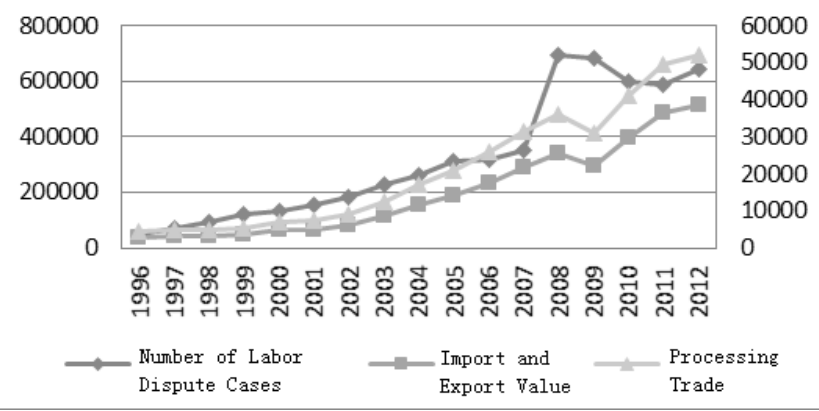

Source: Complied from the China Labor Statistical Yearbook for 1997-2013, China Labor Press, and China Trade and External Economic Statistical Yearbook for 1997-2013, National Bureau

Based on the foregoing, we attempt to find through research what kind of influence foreign trade, especially processing trade emerging from the international division of labor may exert on labor dispute in the development process of labor-capital relation. The profound analysis on the role of trade in troubled relation between labor and capital, determination of conjunction point between employer and employee for profit distribution, discussion on relevant optimal path and optimization of distribution pattern in labor benefit can not only encourage the realization of social equity and justice, but stimulate the enthusiasm for innovation of employer and employee and then promote the transformation and upgrading of processing trade.

The rest of the paper is organized as follows: Section 2 presents the reference for the globalization and labor-capital relation; Section 3 illustrates the variables referred in this paper, data source and model structure; Section 4 makes an analysis on measurement date result and discusses the interaction result between trade and labor dispute and its mechanism of action; we conclude the paper and propose the relevant policy recommendations in Section 5. 


\section{INFLUENCE OF TRADE ON LABOR DISPUTE: LITERATURE REVIEW}

With the in-depth development of globalization, scholars begin to focus on the study of labor right protection, unfortunately, they fail to reach a unanimous conclusion on what kind of influence trade openness may exert on labor right and its mechanism of action (Gallagher, 2005; HafnerBurton, 2005). Some scholars (such as Kucera and Sarna, 2004, Gelleny, \& Sacko 2001) assert that increased trade helps significantly improve labor standards, promote the status of workers, encourage the labor rights protection, improve the situation of workers, rise welfare and wages of workers, all of which ease the increasing contraction between labor and capital, avoid labor dispute and positively lead to "spiral way of rising" labor right. Since the 1980s, developing countries have attempted to stimulate economic growth by developing foreign trade, and labor rights are improved when there is increased consumption and longterm economic growth due to trade openness, significantly promoting the "trading up" of China's labor standards (Garrett, 2000).

At the present stage, the study of labor dispute mainly discusses the influence of trade on domestic labor dispute from the perspective of heterogeneity of home country and host country. Krishna. P and M. Z. Senses (2012) suggest that for North-South trade, developed countries with higher economic development tend to be exposed to a continuous high labor cost as a result of high wages paid to workers, and high labor standards and short working hours with the aid of bargaining power of formal unions. Faced with the impact of products manufactured at lower labor cost in developing countries, traditional industries, especially the manufacturing industry, have to reduce labor cost for survival, or resort to technological innovation for decreased cost or decline at the risk of bankruptcy. In the process of forced transformation of traditional enterprises under the pressure of competition, contradiction between employer and employee standing for opposite benefits is provoked increasingly, and labor organizations led by ILO continue to resort to negotiations, present a protest and even stage a strike. Busse (2004) found a positive correlation between er capita GDP, education background and labor right protection, and a negative correlation between trade openness and labor standards with the civil rights as a proxy variable when civil rights assessed by Freedom House, a U.S.-based non-governmental organization, is introduced as proxy variable for forced labor and union right in his research, showing the fact that trade openness undermines the rights of citizens in short.

On the other hand, these developing countries involved in North-south Trade provide low labor cost owing to economic backwardness and large population base, showing a considerable labor cost advantage in the competition of international trade, upon which, Busse (2002) assumes that the higher proportion of low-skilled labor-intensive product export value in total export value reflects a country's comparative advantage in labor cost, leading to the popularization of forced labor in society, undermined unionization and insufficient protection of labor rights.
By contrast, globalization also exerts negative impact on labor right protection. The reason why multinational corporations prefer outsourced production is to reduce labor costs. For the purpose of cost control, multinational corporations inevitably tend to select countries with lower labor costs, provoking severe competition to attract capital inflow among countries, suppressing the implementation of trade union's activities, eroding the rallies, weakening the legal guarantee of labor right and constantly triggering labor dispute (Drezner, 2001). In transnational empirical study, the result of study by Rodrik (1997) also states labor dispute occurs continuously in a country where investment attraction and improved international competitiveness are made at the sacrifice of welfare of workers and with prejudice to basic rights of workers. Furthermore, Layna Mosley \& Saika Uno (2007) start from the collective labor rights and figure out that based on panel data among countries, economic openness exerts significantly negative effect on presentation of collective labor right. It appears that increased import and export value fails to promote labor right of workers and it seems difficult to achieve win-win situation between employers and employees.

\section{DATA, VARIABLE AND MODEL}

With reference to the existing literature related to labor dispute in an open condition, this paper introduces trade openness and unionization as independent variables and presents the below econometric model to explain the incidence of labor dispute:

$$
\begin{aligned}
& \text { pdispute }_{i t}=\alpha+\beta \cdot \text { openness }_{i t}+\gamma \cdot \text { union }_{i t}+\delta \cdot \text { openness }_{i t} \times \text { union }_{i t} \\
& +\varphi \cdot X_{i t}+\theta_{i}+\mu_{t}+\varepsilon_{i t}
\end{aligned}
$$

Where, $\mathrm{i}$ is province, $\mathrm{t}$ is year, pdispute $_{i t}$ is incidence of labor dispute, openness is trade openness, union is the degree of unionization, $X_{i t}$ is other scalars impacting labor dispute, $\theta_{i}$ and $\mu_{t}$ are unobserved and fixed region and time effect, ${ }_{i t}$ is random error. In addition, the interplay between trade openness and degree of unionization is introduced to analyze its mechanism of action on the incidence of labor dispute mechanisms.

\section{A. Explained Variables}

The explained variables used in this paper refer to the incidence of labor dispute. Labor dispute is a result of provoked contraction between labor and capital and a direction representation of combined effect of various factors impacting labor-capital relation, including labor standards, labor conditions and wages. The data in this paper is extracted from the number of labor dispute cases accepted and heard in current period as described in China Labor Statistical Yearbook. For the assessment in this paper, incidence of labor dispute is employed rather than the absolute number of cases related to labor disputes, given that there is an increased number of labor dispute cases with the population growth in employment, as a consequence, such absolute number can not exhibit the change trend of labor 
dispute with the time and incidence of labor dispute, and incidence of labor dispute is used to exclude the influence of population growth in employment (Cai Fang, 2012), wherein, the incidence of labor dispute can be calculated according to the below formula:

pdispute $_{H, t}=\frac{\text { Workforce Population Involved in Labor Dispute Cases }_{\mathrm{i}, \mathrm{z}}}{\text { Total Population in Employment }_{\mathrm{i}, \mathrm{t}}} * 100$

Wherein, pdispute is the incidence of labor dispute in $\mathrm{i}$ (province) in $\mathrm{t}$ (year). Total population in employment comes from total workforce population as shown in China Labor Statistical Yearbook.

\section{B. Explanatory Variables}

This paper focuses on the research of the impact trade may exert on labor dispute, and based on this, the core of this paper is to explain the foreign trade openness index (openness) and to determine a country's dependence on trade by calculating the proportion of total import and export value in GDP in a region. Econometric model in this paper also provides the following control variables: (1) level of economic development: we represent the natural logarithm of per capita GDP in the model with lnpcgdp, and relevant adjustment is made for it with the year of 1998 as the base period. Considering that potential non-linear characteristics, we also engage the square of lnpcgdp; (2) human capital factor: we introduce the ratio of population with the education background of junior college and above in each provincial as human to assess the human capital; (3) urbanization: the ratio of urban population to total population is used to represent the city rate (city rate), being the contrary indicator to measure the degree of urbanization; (4) level of foreign trade, which is determined through the ratio of total import and export value to GDP for the current year (openness);

This paper mainly overlooks the role foreign trade and processing trade play in labor dispute and the data used in this paper is the inter-provincial panel data which are mainly compiled from China Statistical Yearbook, China Labor Statistical Yearbook, China Union Statistical Yearbook, China Trade and External Economic Statistical Yearbook and the statistical yearbooks for each province. This paper excludes data from Tibet, Hainan and Chongqing for the relative data consistency.

\section{Test RESUlt AND ANALYSIS}

\section{A. Estimation Result of Panel Data Fixed and Random Effects}

Columns (1) to (3) of Table 2 demonstrate the estimation result of panel data fixed and random effects. To compare the applicability of two models, we conduct hausman test and reject null hypothesis at the significance level of $1 \%$, meaning that fixed effect model are more applicable. Therefore, the following analysis is made based on the results of FE in column (1). In addition, considering that increased labor dispute causes the cost growth for enterprises to deal with labor dispute, burdening enterprises with negative cost and refraining enterprises from the development of international trade, we use GMM approach to deal with potential endogenous issues for trade so that the influence of endogenity on estimation result can be eliminated.

TABLE I. ESTIMATION RESUlt OF BASIC MOdEL

\begin{tabular}{|c|c|c|c|}
\hline & (1) & (2) & (3) \\
\hline & FE & RE & Sys-GMM \\
\hline \multirow[t]{2}{*}{ L.pcdispute } & & & $0.750 * * *$ \\
\hline & & & $(0.00559)$ \\
\hline \multirow[t]{2}{*}{ openness } & $-0.122 * * *$ & $-0.0513 * * *$ & $-0.0441 * * *$ \\
\hline & $(0.0363)$ & $(0.0193)$ & $(0.00539)$ \\
\hline \multirow[t]{2}{*}{ union } & $-0.187 * *$ & $-0.191 * * *$ & $-0.0979 * * *$ \\
\hline & $(0.0784)$ & $(0.0542)$ & $(0.0166)$ \\
\hline \multirow[t]{2}{*}{ openness*union } & $0.494 * * *$ & $0.448 * * *$ & $0.215 * * *$ \\
\hline & $(0.0654)$ & $(0.0475)$ & $(0.0133)$ \\
\hline \multirow[t]{2}{*}{ wage } & $-0.169 * * *$ & $-0.174 * * *$ & $-0.0400 * * *$ \\
\hline & $(0.0539)$ & $(0.0570)$ & $(0.00904)$ \\
\hline \multirow[t]{2}{*}{ fdi_flowpc } & $0.253 * * *$ & $0.117 * * *$ & $0.0383 * * *$ \\
\hline & $(0.0433)$ & $(0.0373)$ & $(0.0125)$ \\
\hline \multirow[t]{2}{*}{ In_capitalstock_pc } & $-0.0363 * * *$ & 0.00238 & $0.00331 * * *$ \\
\hline & $(0.0109)$ & $(0.00843)$ & $(0.000519)$ \\
\hline \multirow[t]{2}{*}{ ln_pcgdp } & $0.0514 * * *$ & $0.0296 * * *$ & $0.00756 * * *$ \\
\hline & $(0.00903)$ & $(0.00706)$ & $(0.00101)$ \\
\hline \multirow[t]{2}{*}{ labor } & 0.0311 & $0.0838 * *$ & $-0.0133^{* * * *}$ \\
\hline & $(0.0370)$ & $(0.0391)$ & $(0.00217)$ \\
\hline \multirow[t]{2}{*}{ urban } & -0.00367 & 0.0153 & $-0.0167 * * *$ \\
\hline & $(0.0153)$ & $(0.0158)$ & $(0.000971)$ \\
\hline \multirow[t]{2}{*}{ _cons } & $-0.387 * * *$ & $-0.211 * * *$ & $-0.0317 * * *$ \\
\hline & $(0.0760)$ & $(0.0647)$ & $(0.0109)$ \\
\hline $\mathrm{N}$ & 420 & 420 & 392 \\
\hline
\end{tabular}

With the climbing dependence on foreign trade, the incidence of labor disputes rises steeply. When there is an increase of $1 \%$ in trade, there will be an increase of $0.122 \%$ in the incidence of labor dispute in response, and the results are significant at the $1 \%$ level. Moreover, the degree of unionization impacts positively on labor dispute. The higher the degree of unionization, the higher the incidence of labor dispute can be, and the conclusion is in line with the study result of Cai Fang (2012). The effect of other control variables, including fdi flow (fdi_flowpc), per capita GDP (lnpcgdp), the labor force growth rate (labor), the level of urbanization (urban) are consistent with expectations, in which, wages, as one of important factors causing labor dispute, exert negative impact on the incidence of labor dispute to the extent that increased wage can ease the labor dispute.

\section{B. Mechanism of Action of Trade Openness on Labor Dispute and Its Results}

Although increased trade dependence can induce labor disputes and intensify the conflict between labor and capital, we have no idea how trade may exert influence on labor dispute? With reference to foreign research experience (Saha, Bibhas, K. Sen, and D. Maiti, 2010; Eric Neumayer, 2005;), we can state that for many factors affecting labor disputes, the continuous climb in openness of a country encourages union learning experience from developed countries and 
taking more measures to protect worker's rights, which facilitates right claims of workers involved in labor disputes and then leads to the rising incidence of labor disputes (Krishna and Senses, 2012; ).

Based on the results in Table 2, as shown in column (1), the coefficient of interaction item openness*union is 0.494 , under the premise of growing openness of foreign trade, the higher the degree of unionization is, the higher the incidence of labor dispute will be, showing a positive effect, and based on this, union plays an active role in promoting the workers' right protection and organizing labor movement in an open condition. Nevertheless, in an open condition where labor dispute occurs very frequently in recent years, union is considerably questioned in relation to its role to promote worker's right protection. The collective labor dispute closely related to the role of union accounts for a large proportion of total labor disputes, directly showing the role of union in organizing worker movement for right protection in a collective manner. This paper employs the incidence of collective labor dispute as a dependent variable instead of the incidence of labor dispute with a view of further verifying whether foreign trade provokes increased labor dispute with the involvement of union by virtue of the research of the correlation between collective labor dispute and the degree of unionization.

\section{CONCLUSION}

This paper focuses on the study of the influence of foreign trade on labor dispute in our country by using interprovincial penal data. We introduce the incidence of labor dispute as the explained variable and dependence of trade to assess the situation of foreign trade, and found that the higher the trade openness is, the higher the incidence of labor dispute can be. After adding the interaction item "trade dependence and union", we found that the higher the degree of unionization is, the higher the trade openness can be and the more significant the labor dispute will be. Union plays a considerable role in promoting workers' right protection in an open condition.

The policy implication of this paper is to reveal that in the process of China's further integration in globalization through rapid development of foreign trade, there will be more labor disputes between labor and capital that stand for opposite benefits in respect of wage, benefits and communications. Similar to other developing countries all over the world, enterprises, after entering into new and unfamiliar regulatory environment, are powerless to deal with labor dispute in the pursuit of profit maximization and cost minimization.

Attention should be paid to the issues below in order to improve labor-capital relation: firstly, domestic labor right legal protection system should be further improved to address the infringement of workers' rights; secondly, the status of union should be promoted in respect of Chinese workers' right protection for further enhancing the degree of unionization and encouraging the positive role of union in workers right protection. Finally, considering that processing trade, an important form of participation in the international division of labor for China, is mainly involved in laborintensive manufacturing activities, and compared to the harmonious labor-capital relation for capital-intensive industries, labor-intensive industries feature the higher incidence labor dispute, it is therefore imperative to promote the upgrading of China's foreign trade industry.

This paper, limited to data availability, has shortcomings below: firstly, we fail to examine the mechanism of action of foreign trade to labor dispute from the perspective of collective labor dispute due to data deficiency; secondly, this paper is intended to conduct robustness test starting from processing trade in eastern, central and western regions, but lack of data for central and western processing trade in part makes it difficult for us to successfully complete such test, and in-depth research is to be conducted in the event of availability of such new data.

\section{REFERENCES}

[1] Chang Kai, 2002, WTO, Labor Standards and Labor Rights Protection [J], "Chinese Social Science", 1st Issue.

[2] Shen Kunrong \& Geng qiang. Foreign Direct Investment, Technology Spillover and Endogenous Economic Growth - Econometric Test and Empirical Analysis of Chinese Data [J] Chinese Social Science 2001 (05)

[3] Saha, Bibhas, K. Sen, and D. Maiti. "Trade openness, labour institutions and flexibilisation: theory and evidence from India." Brooks World Poverty Institute Working Paper24.6(2010):180-195.

[4] Krishna, Pravin, and M. Z. Senses. "Trade, Labor Market Frictions, and Residual Wage Inequality across Worker Groups." American Economic Review volume 102.3(2012):417-423(7).

[5] Gertler, Mark, and A. Trigari. "Unemployment Fluctuations with Staggered Nash Wage Bargaining." Computing in Economics \& Finance117.1(2009):38-86.

[6] Kucera, D., 2002, "Core labour standards and foreign direct investment" [J], International Labour Review, 141, 31-69.

[7] Mosley, L. and S. Uno, 2007, "Racing to the Bottom or Climbing to the Top? Economic Globalization and Collective Labor Rights" [J], Comparative Political Studies, 40(8), 923-948. 